\title{
PRECARIZAÇÃO DO TRABALHO E REORGANIZAÇÃO DA MÃO DE OBRA NO CONTEXTO DE PANDEMIA
}

\author{
Precarious work and reorganization of the workforce in the context of a \\ pandemic
}

Aline da Costa Lourenço'

\begin{abstract}
Resumo
Após a crise de 2015-2016, a economia brasileira sofreu um aumento do número de desempregados e devido a recuperação lenta da crise, ocorreu uma ampliação da informalidade no mercado de trabalho. Desta forma, uma das alternativas de milhares de brasileiros foi se adaptar à nova forma de controle, gerenciamento e organização do trabalho, mediado muitas vezes por plataformas digitais, mas não restrito a elas, que se tornou uma tendência mundial, denominada de "uberização". A emergência sanitária, causada pela disseminação mundial da Covid-19 que marcou o ano de 2020, chegou ao Brasil em um contexto em que o mercado de trabalho já precisava de proteção. 0 objetivo deste trabalho é analisar o mercado de trabalho precário do país e a reorganização da mão de obra durante a pandemia. 0 percurso metodológico parte de uma análise da situação do mercado de trabalho antes e durante a pandemia, e uma análise da reorganização dos trabalhadores das plataformas digitais diante da precarização do trabalho intensificada na pandemia. Uma grande parcela da população historicamente não foi incluída no mercado de trabalho formal no País e, diante da pandemia, os trabalhadores que se submetem aos trabalhos mediados por plataformas digitais se organizaram tanto por meio de manifestações para solicitar direitos mínimos de trabalho quanto com a criação de cooperativas.
\end{abstract}

Palavras-Chave: Precarização; Reorganização; Pandemia.

\begin{abstract}
After the 2015-2016 crisis, the Brazilian economy experienced an increase in the number of unemployed, and due to the slow recovery from the crisis, there was an increase in informality in the labor market. Thus, one of the alternatives of thousands of Brazilians was to adapt to the new form of control, management and organization of work, often mediated by digital platforms, but not restricted to them, which has become a worldwide trend, called uberization. The health emergency caused by the worldwide spread of Covid-19 that marked the year 2020 reached Brazil in a context in which the labor market already needed protection. The objective of this work is to analyze the precarious labor market in the country and the reorganization of labor during the pandemic. The methodological path starts from an analysis of the labor market situation before and during the pandemic, and an analysis of the reorganization of workers on digital platforms in the face of precarious work intensified in the
\end{abstract}

\footnotetext{
1 Professora Substituta na Faculdade de Economia da Universidade Federal de Juiz de Fora, em Juiz de Fora, Minas Gerais. Possui mestrado em Economia pela Escola Paulista de Política, Economia e Negócios (EPPEN) da Universidade Federal de São Paulo (2018). Possui graduação em Ciências Econômicas pela Universidade Federal Rural do Rio de Janeiro (2015). E-mail: lourenco.caline@gmail.com Cidade: Juiz de Fora.
} 
Precarização do trabalho e reorganização da mão de obra no contexto de pandemia | Aline da Costa Lourenço

pandemic. a large portion of the population has historically not been included in the formal job market and that in the face of the pandemic, workers who submit to jobs mediated by digital platforms have organized themselves both through demonstrations to request minimum labor rights and with the creation of cooperatives.

Keywords: Precariousness; Reorganization; Pandemic.

\section{Introdução}

A atual fase do capitalismo vem alterando as relações de trabalho de forma constante, destacando-se a precarização do mercado laboral diante do uso de tecnologias digitais.

No Brasil, sempre existiu uma parcela da população que não foi acolhida pelo mercado formal de trabalho. Entretanto, a partir da crise econômica vivenciada a partir de 2015, esta parcela da população elevou-se e, diante da pandemia do coronavirus, intensificou-se ainda mais. Segundo Mattei e Heinen (2019), especialmente devido aos impactos da crise econômica vivenciada pelo país a partir de 2015, a dinâmica do mercado de trabalho foi afetada de tal modo que o número absoluto de desempregados em 2018 praticamente dobrou do registrado em 2012.

Neste contexto, ocorreu um aumento das ocupações vinculadas a aplicativos, possibilitadas principalmente a partir da reforma trabalhista. Estas ocupações caracterizam-se por longas horas de trabalho, má remuneração destes trabalhadores e, durante a pandemia, do aumento do risco de contágio do vírus. Com as medidas quarentenárias, ocorreu um aumento do número de trabalhadores de aplicativos no país e um descaso das plataformas em relação a esses trabalhadores, não fornecendo nenhum equipamento de proteção individual.

Esta forma de ocupação vinculada a aplicativos é denominada por Abílio (2019) como "uberização" do trabalho e corresponde a uma nova forma de gestão, organização e controle do trabalho que se afirma como tendência global no mundo do trabalho, tendo as plataformas digitais como vetores de novas formas de organização do trabalho. Com isso, estabelecem-se diferentes definições sobre diferentes tipos de relações de trabalho mediados por plataformas. 
Precarização do trabalho e reorganização da mão de obra no contexto de pandemia | Aline da Costa Lourenço

Assim, o objetivo deste trabalho é analisar o mercado de trabalho precário do país e a reorganização da mão de obra durante a pandemia. O percurso metodológico parte de uma análise da situação do mercado de trabalho antes e durante a pandemia, através de autores que retratam o tema, dados da PNAD Contínua e PNAD Covid-19, além de uma análise da reorganização dos trabalhadores das plataformas digitais diante da precarização do trabalho intensificada na pandemia.

Para atingir o objetivo proposto, este trabalho se divide em 4 partes além desta introdução. Na seção 2 , realiza-se uma análise do mercado de trabalho brasileiro em diferentes períodos. Na seção 3, analisa-se as tecnologias digitais e as relações de trabalho e na seção 4, a reorganização dessa mão de obra na pandemia. Por fim, breves considerações encerram o artigo.

\section{Mercado laboral brasileiro em diferentes períodos}

\section{Resgate histórico do mercado de trabalho no País: Parcela da população sempre esteve fora do mercado formal}

Cardoso (2019) analisa o processo de desenvolvimento brasileiro entre 1940 e 2010, através dos principais mecanismos pelos quais os trabalhadores foram incorporados à dinâmica socioeconômica, ou seja, por meio da entrada no mercado de trabalho.

Segundo o autor, entre o período de 1940 e 1980, o país passou por um processo de intensa alteração estrutural, devido a um padrão de crescimento econômico denominado de desenvolvimentista que foi dirigido e financiado pelo Estado, em conjunto com capitais nacionais e estrangeiros e fechamento do mercado interno à competição externa. Este padrão, transformou o país de agrário à oitava economia do mundo em 1980. Entretanto, na década de 1980 este padrão de crescimento foi interrompido e sua taxa de expansão passou a ser pequena em relação ao crescimento populacional, gerando queda da renda per capita e aumento expressivo da concentração de renda.

A década de 1980 foi adversa para o país devido à crise da dívida. Com o segundo choque do petróleo em 1979 e a moratória do México, ocorreu uma crise no mercado internacional de crédito que resultou na 
Precarização do trabalho e reorganização da mão de obra no contexto de pandemia | Aline da Costa Lourenço

redução de empréstimo aos países em desenvolvimento. O Brasil precisava saldar suas despesas externas e, como o contexto era de racionamento do financiamento externo, foi realizada uma transferência de recursos do país para o exterior (CARNEIRO, 2002).

Como resposta a crise externa, o governo realizou ajustamento na economia entre 1979-1984. Foram realizados distintos modelos de ajuste externo nesse período, responsáveis não só pela maior recessão já vivida pelo país até então, como pelas mudanças e processos que iriam influenciar a economia ao longo da década e durante a primeira metade dos anos 1990.

Neste período, a inflação era um problema latente atingindo $235 \%$ ao final de 1985. Instalou-se a Nova República em 1985 e, a fim de legitimar o governo Sarney diante da população, foram realizados uma série de planos a fim de estabilizá-la. Entretanto, estes planos não produziram mais do que um represamento temporário da inflação (HERMANN, 2016).

Todo o contexto supracitado implicou de forma direta sobre o crescimento da economia, visto que, enquanto o país se debatia em tentativas de combater à inflação, a indústria deixava de acompanhar os avanços tecnológicos e organizacionais em rápida propagação nas economias desenvolvidas (CASTRO, 2016).

Conforme Cardoso (2019), diante da estagnação da década de 1980, a participação da indústria na riqueza reduziu e só foi retomado a patamares próximos ao dos anos 1950 em 2000. Assim, para o autor, o país passou por dois grandes processos de mudança estrutural no período: até 1980, quando ocorreu a redução da centralidade da agricultura como principal atividade da economia e sua substituição pelas atividades tipicamente urbanas, principalmente a indústria, e partir de 1980, e especialmente nos anos 1990, quando a indústria perde a centralidade que adquiriu pelo processo anterior em razão do crescimento maior dos serviços. Esse último processo ocorreu, especialmente em virtude da desindustrialização ocorrida após a abertura comercial, associada ao câmbio valorizado que expôs os produtores nacionais que anteriormente eram protegidos pelo fechamento da economia, à competição externa. 
Precarização do trabalho e reorganização da mão de obra no contexto de pandemia | Aline da Costa Lourenço

Ao acompanhar a mudança de eixo do motor da acumulação, a população migrou de forma intensa para as cidades neste período. Em 1940, aproximadamente $2 / 3$ dos brasileiros residiam no campo e 1/3 no mundo urbano. Já em 1980, ocorreu o contrário, com 2/3 da população vivendo nas cidades. Este processo aprofundou-se nas décadas seguintes ao ponto em que em 2000, 80\% da população brasileira estava fora do campo e, em 2010, essa porcentagem chegava à 90\%.

Desta forma, para Cardoso (2019), apesar da indústria ter prevalecido como principal eixo do motor de acumulação capitalista no Brasil durante o período desenvolvimentista, o emprego neste setor foi sempre inferior à riqueza por ele produzida. Assim, em 1980, enquanto o setor industrial era responsável por 44\% do PIB, empregava apenas $25 \%$ dos brasileiros. Logo, a razão entre a participação no PIB e participação no emprego foi sempre muito alta no caso da indústria se comparada às outras atividades urbanas, o que se rompeu apenas na década de 1990 com a redução da participação da indústria no PIB. Assim, o autor acredita que a urbanização nunca foi sinônimo de industrialização do emprego. Ou seja, ocorreram crescentes migrações do campo para a cidade, sem que o setor que gerava as melhores ocupações fosse capaz de absorvê-las.

Além disso, o autor destaca que a renda do trabalho urbano permaneceu muito baixa no Brasil ao longo de todo o período de desenvolvimento industrial do país. A baixa renda igualou ocupados rurais e citadinos ao longo da história de mudança estrutural do país e até muito recentemente. A realidade mudou um pouco em 2010, com a política de valorização do salário mínimo ao longo da primeira década do século XXI.

A política econômica do governo Lula foi nitidamente norteada pelo controle da inflação e a redução da dívida pública, por meio de uma política monetária austera, elevados superávits fiscais e taxa de câmbio apreciada, além de reformas estruturais condizentes com as diretrizes que prevaleciam no governo anterior (NASSIF, 2015). Na perspectiva de Medeiros (2017), sob este novo governo, as reformas liberalizantes dos anos 1990 não prosseguiram. Contudo, não foram criados novos mecanismos substitutos de coordenação e de política industrial e tecnológica cruciais para enfrentar 
Precarização do trabalho e reorganização da mão de obra no contexto de pandemia | Aline da Costa Lourenço

novos desafios produtivos, nem tampouco foram equacionadas, sequer revertidas, as privatizações da década anterior.

Com a alta no ciclo de liquidez internacional, houve uma elevação na entrada de recursos externos além de uma redução na taxa de juros internacionais, o que favoreceu a redução da taxa de juros doméstica, ainda que de forma lenta na economia brasileira. A retomada do crescimento econômico mundial conduziu também a um aumento da demanda por produtos brasileiros para exportação, beneficiados pelo vigoroso aumento dos preços das commodities, principal gênero de mercadorias exportado pelo país (CARCANHOLO, 2010). Assim, em 2004, o crescimento do PIB iniciou uma sequência de cinco anos em alta, com média em torno de 4,5\% ao ano.

De acordo com Carvalho (2018), esse crescimento no Brasil foi marcado pela diminuição de vários indicadores de desigualdade e ampliação do nivel de emprego formal, processo este que foi favorecido tanto pelo cenário internacional favorável quanto pelas politicas redistributivas e os investimentos em infraestrutura física e social. Segundo a economista, o modelo de desenvolvimento deste governo teve alguns pilares que proporcionaram o crescimento mais inclusivo, entre eles, a distribuição de renda na base da pirâmide.

Entre 2003 e 2005, o governo Lula realizou politicas de transferência de renda amplas e universalizadas com a criação do Bolsa Família. O programa $^{2}$ foi criado em 2003 e foi responsável por uma diminuição nos indices de pobreza e na desigualdade de renda no país. Destaca-se também, a valorização mais rápida do salário mínimo a partir de 2005, que teve como efeitos o aumento do salário médio e da participação dos salários na renda da economia e a redução da diferença entre salário mínimo e o salário médio da economia, reduzindo a disparidade salarial. De acordo com Serrano e Summa (2018), no Brasil, o salário minimo atinge direta e indiretamente as condições gerais do mercado de trabalho e o poder de barganha dos trabalhadores em geral. Ademais, visto que diversos beneficios e

2 O Bolsa Família é a integração com maior dinamismo de programas da era FHC, como vale gás, bolsa escola, cesta básica, etc. Além disso, esta é uma política incentivada pelo FMI (ARAUJO et al., 2013). 
Precarização do trabalho e reorganização da mão de obra no contexto de pandemia | Aline da Costa Lourenço

transferências sociais estavam atrelados ao valor do salário mínimo, a elevação dos mesmos teve um forte impacto na redução da pobreza familiar e melhora das condições de vida.

Além disso, destacam-se as alterações no grau de disparidade entre remunerações dos diferentes trabalhadores do mercado formal e o índice de Gini para salários passa por uma contração nos anos 2000, o que revela uma queda da desigualdade salarial. Essas transformações refletiram no padrão de consumo das famílias brasileiras, o qual passou a incluir a população de baixa renda no mercado de consumo de produtos e serviços, o que antes eram consumidos só pelos mais ricos (CARVALHO, 2018).

De acordo com Rugitsky (2016), o aumento do poder de consumo da parcela mais pobre neste período instigou a demanda por alimentos e ampliou o comércio popular, gerando vagas para trabalhadores menos qualificados, de forma a reduzir a disparidade salarial, o que proporcionou a ampliação do mercado.

Bielschowsky (2014) usa a ideia de frentes de expansão para explicar o desenvolvimento do país neste período, que consistem em motores do crescimento econômico. Para o autor, há três frentes de expansão que estiveram presentes na economia brasileira: um amplo mercado interno; uma forte demanda interna e externa por recursos naturais do país, e perspectivas favoráveis em relação à demanda estatal e privada por investimentos em infraestrutura. Neste contexto, caberia ao Estado atuar sobre esses motores de crescimento a fim de garantir o crescimento e o desenvolvimento. Estas frentes de expansão foram otimizadas por políticas sociais redistributivas, como o aumento do salário mínimo e as transferências de renda. Estas políticas possibilitaram agregar mais pessoas ao consumo de massa, recuperação da capacidade de planejamento e investimento do setor público associados a mudanças nas regras fiscais para favorecer o investimento, forte aumento do crédito e aumento dos preços internacionais de commodities, devido ao efeito China.

Para Carneiro (2019), ao combinar politicas salariais restritivas e oferta abundante de mão de obra despossuída e pouco qualificada de pessoas que vieram para as cidades com a intensa migração interna, atraída 
Precarização do trabalho e reorganização da mão de obra no contexto de pandemia | Aline da Costa Lourenço

ou não pela ilusão dos direitos do trabalho, contribuiu-se para depreciar a renda de todos.

Assim, a população brasileira de baixa escolaridade, em grande parte oriunda do campo ou tendo seus pais com origem ali, foi atraída para as cidades com expectativas de melhoria de vida. Entretanto, encontrou empregos de péssima qualidade, mesmo quando formalmente estruturados. Deste modo, o autor afirma que indicadores relevantes em relação a este fato são a relativa estagnação da renda do trabalho entre 1960 e 2010, e, do ponto de vista das oportunidades efetivamente existentes de inserção ocupacional dos migrantes e seus filhos e netos: a real capacidade de o Estado de auxílio a todas as ocupações e o tempo de emprego das pessoas nas ocupações existentes. Isto posto, os empregos formais, em princípio de melhor qualidade, dado que proporcionam acesso aos direitos do trabalho, parecem ser, historicamente, de curta duração mesmo para trabalhadores no auge de sua vida produtiva. Nas palavras do autor:

\begin{abstract}
Ademais, considerando três indicadores centrais de qualidade de emprego (renda, taxa de formalidade e tempo de emprego dos ocupados), tudo indica que as mudanças no mercado de trabalho nos últimos 40 anos, com deslocamento do emprego industrial em favor dos serviços urbanos, não afetou diretamente, em âmbito nacional, a estrutural precariedade das ocupações, que, desse ponto de vista, marca o desenvolvimentismo desde sempre. O que mudou foi a quantidade de empregos disponiveis nacionalmente, que, crescendo a taxas menores do que o crescimento da PEA, resultou em aumento do desemprego global e dos jovens em particular, como veremos no capítulo seguinte. É esse ambiente de oportunidades precárias, instáveis e mal remuneradas em termos médios que os brasileiros encontraram ao longo das últimas décadas (CARDOSO, 2019, p. 283).
\end{abstract}

\title{
Economia e mercado de trabalho de 2015 a 2019
}

De acordo com Mello e Rossi (2018), o governo Dilma fez uma troca de equipe econômica no início do segundo mandato, realizando ajustes na economia, com ajuste fiscal, medidas restritivas de política monetária, cambial, creditícia e em outras esferas de atuação do Estado. O foco era equilibrar os preços relativos, retomando a gestão do tripé macroeconômico por meio do reajuste dos preços administrados defasados, liberalização da gestão da taxa de câmbio, retirada dos incentivos fiscais setoriais, eliminação do crédito subsidiado e colocando a política monetária em seu 
Precarização do trabalho e reorganização da mão de obra no contexto de pandemia | Aline da Costa Lourenço

ponto de equilíbrio. O ponto central consistia na recuperação das contas públicas e redução da inflação, levando-a para o centro da meta. Para isso, junto ao ajuste fiscal seria realizado um aumento dos juros.

Em relação à política monetária no segundo mandato da presidente Dilma, esta foi marcada pelo aumento da taxa de juros, como uma forma de conter a inflação, e pela retração do crédito. Entretanto, essas medidas não foram capazes de reverter a tendência de aumento dos preços no curto prazo.

O problema da inflação se agravou logo no início de 2015, quando os preços administrados, que foram represados, foram liberados de uma vez só. Diante do choque dos custos, o Banco Central tratou a inflação promovendo aumentos cada vez maiores da taxa Selic.

Quanto à politica cambial, a nova equipe econômica sinalizou ao mercado o fim do programa de swap e uma politica cambial mais flexível e menos intervencionista, ou seja, seguiria o rumo apontado pelo mercado. $\mathrm{Na}$ prática, o Banco Central sinalizou ao mercado que o mesmo poderia apostar contra a sua posição e que não haveria intervenção de forma incisiva.

Como resultado da política de austeridade deste período, os autores afirmam que não houve melhoria das contas públicas, pelo contrário, acentuou-se a deterioração fiscal, redução da confiança empresarial e do investimento privado, e a inflação rompeu o teto da média, o que transformou a desaceleração da economia em uma recessão.

A estratégia do governo não se limitou ao ajuste fiscal e acelerou o ajuste de preços relativos, principalmente da relação cambio/salário, estabelecido em 2011, ao contrário da proposta de ajuste gradual feita em campanha eleitoral. Não focava apenas na desvalorização cambial, mas também na redução de salários reais e do nível de emprego.

Segundo Carvalho (2018), esse contexto foi sentido pelo mercado de trabalho. O desemprego maior e a redução do poder de barganha dos trabalhadores reduziram o salário real médio, o que reverteu rapidamente a redução da desigualdade salarial obtida nos anos 2000. Com isso, as famílias reduziram seus gastos a fim de honrar seus compromissos financeiros, impactando o nível de consumo. 
Precarização do trabalho e reorganização da mão de obra no contexto de pandemia | Aline da Costa Lourenço

Desta forma, de acordo com Pochmann (2015), o ano de 2015 pode ser considerado um ponto de inflexão no comportamento do mercado de trabalho, visto que ocorreu uma trajetória ascendente da taxa de desemprego no país, consequência direta da implementação das políticas de ajuste econômico que levaram à recessão. Assim, devido a intensificação do desemprego neste período, o autor considera o ano 2015 como o terceiro momento temporal de ajuste econômico mais grave observado nas últimas três décadas. Não só o desemprego voltou a crescer rapidamente, como também o salário médio dos ocupados perdeu poder aquisitivo nos primeiros sete meses de 2015. Para o autor, a adoção das políticas de ajuste provocou a recessão da economia nacional e, consequentemente, maiores implicações sobre a quantidade da mão de obra ocupada do que os salários recebidos pelos trabalhadores.

Além do mais, o autor destaca que o aumento do desemprego não ocorreu de modo homogêneo entre os trabalhadores, haja vista que fora mais intenso para pessoas do sexo feminino, com mais idade, menor escolaridade, na condição de chefe de família, situados nas regiões metropolitanas do Rio de Janeiro e Porto Alegre e relacionado com as atividades do trabalho doméstico, da construção civil e da indústria.

Com o rebaixamento da renda dos ocupados, tende a ocorrer o maior acirramento da competição entre os trabalhadores ocasionado por aqueles que perdem o emprego e pelos novos ingressantes no interior do mercado de trabalho. Assim, a procura por trabalho sofre um impulso maior devido ao movimento de solidariedade impulsionado no interior dos domicílios pela diminuição da renda média familiar per capita.

Após a recessão aguda de 2014/2016, a economia do país sofreu uma interrupção do crescimento ascendente que o país vivenciou até 2010, e caracterizou-se por uma situação que Obreiro e Paula (2019) denominaram de estagnação, isto é, uma economia com crescimento baixo e estável, em torno de $1 \%$ ao ano entre 2017 e 2019. Os autores destacam fatores conjunturais e estruturais que contribuíram para manter a economia brasileira estagnada. No que se refere aos fatores conjunturais, os autores destacam a falta de demanda decorrente de um conservadorismo excessivo 
Precarização do trabalho e reorganização da mão de obra no contexto de pandemia | Aline da Costa Lourenço

da política econômica, com a manutenção de uma política monetária contracionista por um longo período, ao mesmo tempo em que a política fiscal e a financeira também foram contracionistas. Outro fator destacado pelos autores refere-se ao colapso no mercado de crédito a partir de 2015, devido à combinação de aumento no endividamento dos agentes com um elevado choque de juros.

Além disso, o elevado endividamento das firmas e das famílias gerou uma redução do nível de atividade econômica e demanda agregada, em razão do processo de desalavancagem das firmas e das famílias. Por fim, os autores destacam a tendência de deterioração na economia internacional que atingiu a economia brasileira tanto nos fluxos de comércio quanto nos fluxos financeiros. Quanto aos fatores estruturais, os autores destacam a tendência à desindustrialização da economia brasileira.

Mattei e Heinen (2019), traçam um panorama do mercado de trabalho brasileiro. Segundo estes autores, a crise econômica afetou o mercado de trabalho em conjunto com diversos problemas interrelacionados. Assim, os autores destacam o comportamento da PEA Desocupada, que voltou a crescer fortemente após a emergência da crise e se estabilizou no patamar de 12\% em 2018, significando que o desemprego aberto atingiu mais de 12 milhões de brasileiros.

Principalmente por conta de seus impactos entre 2015 e 2017, a crise econômica afetou a dinâmica do mercado de trabalho de tal modo que o número absoluto de desempregados em 2018 foi praticamente o dobro do registrado em 2012. Em relação aos setores de atividade onde os trabalhadores exercem sua jornada de trabalho, os autores observaram que os ramos da indústria geral e da construção civil aceleraram o ritmo das demissões a partir de 2015, sendo esses dois setores os maiores responsáveis pela expansão do desemprego, cujas taxas só não foram ainda mais elevadas devido ao bom desempenho do setor terciário, principalmente dos ramos de alojamento e alimentação; comércio e reparação de veículos; e o grupo da administração pública e demais setores a ele vinculados.

No que se refere a categoria das ocupações, os autores destacam que o grupo dos empregados, mesmo tendo redução em sua participação, ainda 
Precarização do trabalho e reorganização da mão de obra no contexto de pandemia | Aline da Costa Lourenço

se mantiveram como a maior categoria dentre todas as posições na ocupação. Contudo, os autores destacam o aumento dos trabalhadores por conta própria no agregado nacional, o que, para eles, poderia ser um sinalizador do processo de precarização das condições de trabalho, devido ao caráter informal, a elevada jornada de trabalho e as baixas remunerações médias dessa categoria.

Além disso, segundo Mattei e Heinen (2019), este processo de precarização das condições de trabalho também aparece de modo bastante visivel quando são analisadas as relações formalizadas de trabalho, visto a queda expressiva das contratações com carteira de trabalho assinada a partir de 2015. Assim, os autores ressaltam que as taxas de informalidade existentes em 2018 são elevadas e podem indicar uma degradação das condições de trabalho no Brasil.

Mattei e Heinen (2019) ainda identificam outros aspectos da precarização do mercado de trabalho, como as medidas de subutilização da força de trabalho, que puderam ser captados graças à nova metodologia da PNAD Contínua, verificando-se, desta forma, que, além do desemprego aberto, expandem-se o desemprego oculto, observado em duas outras formas: a população subocupada por insuficiência de horas trabalhadas dobrou entre 2014 e 2018 e a força de trabalho potencial aumentou expressivamente. Quando essas duas modalidades de desemprego são somadas ao desemprego aberto, tem-se 27 milhões de pessoas em 2018 em condições de subutilização. Os autores ainda destacam baixos níveis de rendimento das categorias com ocupações informais e a reforma trabalhista, que visou a flexibilização da legislação trabalhista como instrumento de combate ao desemprego, mas que destruiu o papel dos sindicatos no disciplinamento das relações trabalhistas ao retirar dos mesmos atribuições e prerrogativas inerentes à sua função econômica, social e política, tornando facultativa a contribuição sindical, estratégia adotada com a intenção de asfixiar financeiramente os sindicatos.

Além disso, a reforma legalizou o trabalho intermitente, modalidade na qual o empregador tem a seu dispor uma determinada força de trabalho em tempo integral, contudo remunera apenas pelas horas efetivamente 
Precarização do trabalho e reorganização da mão de obra no contexto de pandemia | Aline da Costa Lourenço

trabalhadas, o que, para os autores, levará a um processo de pauperização de importantes segmentos da classe trabalhadora que, diante de um cenário de desemprego elevado, se veem submetidos a essa condição.

Em 2019, iniciou-se o governo Bolsonaro e a partir de então, segundo Oreiro e Paula (2019), a política ortodoxo-liberal adotada por Temer/ Meirelles foi aprofundada por Bolsonaro/Guedes por meio da realização de uma forte contração fiscal, principalmente dos gastos correntes e um conjunto de políticas liberais que objetiva desregulamentar os mercados e permitir que a iniciativa privada comandasse o processo econômico. $\mathrm{O}$ objetivo era adotar medidas de austeridade fiscal, inspiradas na hipótese de ajuste fiscal contracionista, na qual uma contração fiscal seria capaz de aumentar a confiança do setor privado e estimular novas decisões de consumo e investimento.

Segundo Cardoso Jr (2019), as pretensões governamentais e o desempenho estatal do governo Bolsonaro visavam moldar o Estado brasileiro de modo a implementar ou atingir seus objetivos estratégicos através do desmonte do Estado brasileiro de forma intensificada.

\section{Desenvolvimento capitalista, tecnologias digitais e relações de trabalho}

Fontes (2017) relata a tensão sob o capital, ao estabelecer um grande número de trabalhadores em espaços comuns subordinados à mesma empresa, visto que possuíam os mesmos hábitos de vida, locais de moradia e um cotidiano compartilhado por anos. Os Estados capitalistas diminuiram sua intervenção na reprodução da força de trabalho empregada, e aumentaram a contenção da massa crescente de trabalhadores desempregados, preparando-os para a subordinação direta ao capital. Outro aspecto relevante é a diminuição dos recursos disponíveis para o Estado pela redução de suas fontes de recursos e pelo aumento da ambição do capital captando recursos públicos para sua expansão internacional e/ou em momentos de crise. Neste contexto, há procedimentos empresariais e/ou políticos colocados em prática como superposição de sucessivas formações profissionais a fim de adequar os seres sociais às necessidades específicas do capital, estímulo à participação e engajamento do trabalhador e estímulo ao empreendedorismo, como forma de apagar a relação de subordinação 
Precarização do trabalho e reorganização da mão de obra no contexto de pandemia | Aline da Costa Lourenço

entre o trabalho e o capital. A autora destaca a relação entre o trabalhador e a tecnologia, que apesar de ser fruto do trabalho humano, torna-se uma ameaça ao emprego, ao substituir seres concretos em funções que serão eliminadas pelo uso da mesma.

Atualmente vigoram diversas formas de subordinação direta dos trabalhadores às mais variadas formas de capital. Neste contexto, além dos empregos com contratos regulares, há formas paralelas, com contratos parciais, terceirizações em vários níveis, subordinação sem contrato, salário por peça, trabalho à domicílio, pessoa jurídica e a "uberização" das relações de trabalho. Segundo Abílio (2019), apesar da visibilidade gerada pelo grande número de motoristas Uber no Brasil e no mundo, a "uberização" não se inicia com a atuação desta empresa e não se limita a ela. Esta atualização da forma de trabalho vem da flexibilização do trabalho e de um contexto de décadas de políticas neoliberais que estabelecem novas formas de organização do trabalho, eliminação dos direitos trabalhistas, integração de mercados, liberação de fluxos financeiros de investimento. Segundo a autora, a "uberização" do trabalho se refere a uma nova forma de gestão, organização e controle do trabalho que se afirma como tendência global no mundo do trabalho, tendo as plataformas digitais como vetores de novas formas de organização do trabalho. Assim, estabelecem-se diferentes definições sobre diferentes tipos de relações de trabalho mediados por plataformas.

Segundo Antunes e Filgueiras (2020), as plataformas digitais, apesar de não designarem exatamente os mesmos processos, se aproximam por se relacionarem ao uso de ferramentas digitais e da internet, a fim de gerir a produção e o trabalho, como os aplicativos. Os autores apresentam diversos termos para definir transformações nos negócios do capital e no mundo do trabalho relacionadas ao uso de novas tecnologias, como Gig-economy, platform economy, sharing economy, crowdsourcing, on-demand economy, "uberização", crowdwork, trabalho digital, entre outros.

Para Abílio (2019), as plataformas são as novas formas de dispersar o trabalho sem perder o controle sobre ele. De acordo com a autora, isso já era evidente nas cadeias produtivas globais e suas enormes redes de 
Precarização do trabalho e reorganização da mão de obra no contexto de pandemia | Aline da Costa Lourenço

subcontratação. Contudo, isto agora se evidencia em uma multidão de trabalhadores subordinados a uma única empresa, que consolida o trabalhador como um auto gerente-subordinado que não é contratado, e sim se engaja no trabalho por meio da adesão às plataformas. Com isso, o trabalhador uberizado fica desprovido de garantias, direitos ou segurança associados ao trabalho, arca com riscos e custos de sua atividade, fica disponivel ao trabalho e é recrutado e remunerado sob novas lógicas. O desenvolvimento tecnológico atual trouxe mudanças qualitativas à gestão do trabalho. Ocorreu um mapeamento pleno do processo de trabalho, do processamento de dados em grande escala e do gerenciamento combinado e simultâneo de várias informações que a autora denomina de gerenciamento algorítmico do trabalho. Mesmo assim, as empresas-aplicativo se apresentam como mediadores entre oferta e procura, e negam a subordinação e vínculos empregatícios nessa intermediação.

De acordo com Antunes e Filgueiras (2020), as corporações alegam que: i) são empresas de tecnologias digitais; ii) fazem a intermediação de atividades nas quais trabalhadores ofertam serviços de forma autônoma; iii) convertem a força de trabalho em clientes; iv) eliminam a subordinação, alegando liberdade para trabalhar quando, onde e como quisessem.

A "uberização" conta com a disponibilidade do trabalhador, que não tem qualquer possibilidade de negociação ou influência na determinação da distribuição de seu próprio trabalho nem sobre o valor do mesmo. Além disso, a empresa o utiliza apenas quando necessário, de modo automatizado e controlado. A autora denomina este trabalhador como trabalhador just-intime:

Ser just-int-time significa que são transferidos ao trabalhador custos e riscos da atividade; que este está desprovido de direitos associados ao trabalho, enfrentando também a total ausência de garantias sobre sua carga de trabalho e sua remuneração. Nada está garantido (ABÍliO, 2019, p. 3).

Abílio (2019) destaca que com a "uberização", as empresas não podem demitir, pois não contratam. Contudo, podem desligar o trabalhador da plataforma, o que pode ocorrer por vários motivos. 
Precarização do trabalho e reorganização da mão de obra no contexto de pandemia | Aline da Costa Lourenço

Assim, para Antunes e Filgueiras (2020), a grande inovação introduzida pelas novas tecnologias, além de aumentar as formas de obtenção de lucros e extração do mais valor, permite que as empresas usem essas ferramentas como instrumento sofisticado de controle da força de trabalho, com o registro em tempo real da realização de cada tarefa, velocidade, tudo sob o comando de algoritmos, o que os autores denominaram de novo fetiche do mundo tecnológico do capital. Isso permite que se expanda a ideia fetichizada de que tudo está sob o controle de uma tecnologia neutra, enquanto é a engenharia informacional do capital que de fato comanda o algoritmo. Ou seja, os algoritmos são programas comandados por corporações globais, a fim de processar grande volume de informações, o que possibilita direcionar a força de trabalho de acordo com a demanda em todos os seus momentos. Desta forma, diversos trabalhadores ficam à disposição da plataforma e competem entre si, permitindo que haja a possibilidade de rebaixamento salarial. Logo, há ampla flexibilidade para as empresas, contudo, para os trabalhadores é apenas aparente, visto que trabalham mais para garantir sua sobrevivência e manutenção do instrumento de trabalho.

Segundo Abílio (2019), neste contexto, o conceito de empreendedorismo ganhou novos usos e significados. A figura do empresário-agente inovador que irrompe com os padrões de produção, portando criatividade, ousadia, ideias, capital e disposição para assumir riscos é substituída pela ideia de empreendedorismo atual, na qual se refere aos processos de informalização do trabalho e transferência de riscos para o trabalhador, que continua sendo subordinado como trabalhador, entretanto, passa a ser apresentado como empreendedor. Ou seja, o empreendedorismo tornou-se sinônimo de assumir riscos da própria atividade e transfere ao indivíduo a responsabilidade por sua sobrevivência, em um contexto de incerteza e precariedade. Assim, com a "uberização", essa ideia de empreendedorismo obscurece as relações entre capital e trabalho.

Assim, conforme destaca Abílio (2020), no princípio de 2019, segundo os dados da PNAD, 3,8 milhões de brasileiros tinham no trabalho por aplicativo a sua principal fonte de renda. Com isso, para a autora, a 
Precarização do trabalho e reorganização da mão de obra no contexto de pandemia | Aline da Costa Lourenço

reconfiguração do mundo do trabalho nos últimos tempos deixou claro que é possivel dispersar o trabalho sem perder o controle sobre ele. Dispersão esta que veio acompanhada da transferência de riscos e custos das empresas soberanas para as empresas e os trabalhadores a elas subordinados.

De acordo com o Departamento Intersindical de Estatística e Estudos Socioeconômicos (DIEESE, 2020), diante de diversas modificações realizadas pela Reforma Trabalhista de 2017 , verificou-se a criação do contrato de trabalho intermitente, no qual o trabalhador fica disponivel para trabalhar, aguardando, sem remuneração, até ser chamado pelo empregador. Quando é chamado para realizar algum serviço, a renda é proporcional às horas efetivamente trabalhadas.

Conforme dados divulgados pela Relação Anual de Informações Sociais do Ministério da Economia (Rais/ME), ao fim de 2018, a remuneração mensal média para cada vínculo intermitente foi de $\mathrm{R} \$ 763$ contando os meses a partir da admissão, trabalhados ou não - 80\% do salário mínimo. Em relação aos que trabalharam no final de 2018, 43\% receberam renda inferior a um salário mínimo ( $\mathrm{R} \$ 954)$, e apenas $17 \%$ dos vínculos intermitentes geraram remunerações equivalentes a dois salários mínimos ou mais ( $R \$ 1$ 1.908). Desta forma, observa-se que o trabalho intermitente se caracteriza pela instabilidade, visto que não garante nem trabalho nem renda para os trabalhadores contratados nessa categoria.

\section{Pandemia e reorganização da mão de obra}

Uma epidemia do novo coronavirus iniciou-se em 2019 numa região chinesa e em 2020 rapidamente propagou-se por todo o mundo, transformando-se em uma pandemia. Conforme orientações da Organização Mundial da Saúde (OMS), diversos países adotaram medidas de isolamento social e de quarentena a fim de impedir a propagação da doença. No Brasil, apesar da ausência de uma política nacional abrangente de distanciamento social em virtude da atitude negacionista do presidente, medidas de isolamento foram inicialmente adotadas de modo descentralizado por governos estaduais e prefeituras.

Segundo Carvalho (2020), a crise intensificada pela Covid-19 tem proporções e características inéditas. Para a autora, o fechamento 
Precarização do trabalho e reorganização da mão de obra no contexto de pandemia | Aline da Costa Lourenço

obrigatório de setores econômicos inteiros tem repercussão direta nos níveis de produção, ao contrair o Produto Interno Bruto (PIB) pelo lado da oferta de bens e serviços. Todavia, a crise também se dá pelo lado da demanda devido tanto às restrições de circulação dos consumidores quanto ao receio de contágio pelo vírus e à diminuição das exportações decorrente do colapso da renda e do comércio mundial. Nas palavras da autora: "A pandemia provoca um curto-circuito macroeconômico, pois o distanciamento entre produtores e consumidores transforma-se em choque negativo tanto para a oferta quanto para a demanda. Tudo ao mesmo tempo" (CARVALHO, 2020, p. 17).

As medidas destinadas para mitigar a recessão intensificada pela pandemia e evitar uma longa depressão econômica distanciam-se da macroeconomia convencional, visto que esta crise é diferente das demais, tanto por suas origens quanto pela resposta do Estado. Diante da pandemia, as transformações tecnológicas e digitais foram aceleradas e fragilizaram ainda mais as relações trabalhistas, dado que o trabalho remoto e o trabalho por aplicativo aumentaram em meio as medidas quarentenárias. Esta tendência favorece o aumento das jornadas de trabalho, a volatilidade da renda e a perda de direitos trabalhistas mínimos.

Desta forma, segundo a PNAD Covid-19, em agosto de 2020, dos 211,3 milhões de residentes no país, 170,3 milhões correspondem à população em idade de trabalhar (14 anos ou mais de idade), que se dividem em população ocupada, população desocupada e população fora da força de trabalho, como verificada na tabela a seguir:

TABELA 1 - POPULAÇÃO EM IDADE DE TRABALHAR (14 ANOS OU MAIS DE IDADE)

\begin{tabular}{cccc}
\hline & Maio & Julho & Agosto \\
\hline População Ocupada' $^{1}$ & 84,4 & 81,5 & 82,1 \\
População desocupada' & 10,1 & 12,3 & 12,9 \\
População fora da força de trabalho' $^{1}$ & 75,4 & 76,5 & 75,2 \\
Nível de Ocupação $^{2}$ & $49,7 \%$ & $47,9 \%$ & $48,2 \%$ \\
\hline
\end{tabular}

${ }^{1}$ Milhões de pessoas ${ }^{2}$ Percentual de pessoas ocupadas em relação às pessoas em idade de trabalhar. Fonte: PNAD Covid-19. Elaboração Própria. 
Precarização do trabalho e reorganização da mão de obra no contexto de pandemia | Aline da Costa Lourenço

De acordo com a pesquisa realizada por Abílio et al., (2020), dos 270 trabalhadores entrevistados, $47,4 \%$ declararam possuir um rendimento semanal de até $R$ \$ 520,00 e 17,8\% declararam remuneração de até $R \$ 260$ por semana. Contudo, durante a pandemia, a quantidade de entregadores que possuem remuneração menor que $R \$ 260$ semanais passou para $34,4 \%$ dos entrevistados. Logo, verifica-se que o número de trabalhadores inseridos nas faixas de remuneração maiores diminuiu praticamente $1 / 3$. Assim, para Abílio et al., (2020), esta queda na remuneração leva a algumas conclusões, como o aumento do número de cadastro de novos trabalhadores nos últimos meses e o valor da hora de trabalho e/ou bonificação foram reduzidos durante a pandemia, devido ao crescimento significativo do número de entregas. Dentre a população ocupada, a pesquisa revela que o número de pessoas consideradas como trabalhadores informais foi de 27,9 milhões de pessoas em julho, equivalente a 33,9\% do total de ocupados, não havendo variação significativa em relação a julho.

No que se refere à ocupação de entregador de mercadorias (de restaurante, farmácia, loja, Uber Eats, IFood, Rappi etc.), há cerca de 646 mil trabalhadores no Brasil, sendo $94 \%$ homens e $62 \%$ negros. O rendimento médio destes trabalhadores em maio de 2020 foi de $R \$ 1.142$, cerca de $18 \%$ a menos do que o habitual. Quanto à ocupação de motorista (de aplicativo, de táxi, de van, de mototáxi, de ônibus), há cerca de 2,1 milhões de trabalhadores, dos quais 95\% eram do sexo masculino e 59\% eram negros.

De acordo com Salomão (2020), devido à pandemia da Covid-19, ocorreu um aumento do número de entregadores de aplicativos, como na empresa Rappi, que se estima um pico de $300 \%$ no crescimento do número de pedidos de cadastros de entregadores em sua plataforma. Já a 99Food, teve um aumento de $20 \%$ no número de pedidos e o IFood constou com um aumento de 23 mil de entregadores registrados entre fevereiro e março de 2020.

Com base no estudo sobre as condições de trabalho de Entregadores via Plataforma Digital durante a pandemia da Covid-19, das principais empresas detentoras de plataformas digitais no Brasil, especialmente IFood, Uber Eats, Rappi e Loggi, realizado por Abílio et al., (2020), observa-se que 
Precarização do trabalho e reorganização da mão de obra no contexto de pandemia | Aline da Costa Lourenço

há a manutenção de longas horas de trabalho, somada à diminuição da remuneração desses trabalhadores e ao aumento do risco de contágio do vírus, ampliando a precariedade e insegurança das condições de trabalho dos entregadores. De acordo com a pesquisa, durante a pandemia, o período de trabalho dos entregadores permaneceu elevado. Verificou-se que 56,7\% destes trabalham mais de nove horas diárias e 78,1\% realizaram atividade de entrega em seis dias ou mais por semana, demonstrando uma elevada carga horária. Contudo, o longo tempo de trabalho não foi recompensado na remuneração, visto que ocorreu uma diminuição de trabalhadores nas faixas remuneratórias mais altas. Verificou-se também, através dos dados relacionados ao tempo de trabalho e à remuneração, que a atividade de entrega via plataforma digital é a principal fonte de renda destes trabalhadores.

Quanto às medidas de proteção, diante da pandemia, os trabalhadores de aplicativos adotaram tais medidas e as custearam por conta própria, enquanto as empresas se limitaram apenas a prestar orientações. Assim, dado que os trabalhadores precisam custear as medidas de proteção, isto reduz ainda mais a sua remuneração.

Diante disto, a Federação dos motoristas por aplicativo no Brasil (FEMBRAPP) publicou uma nota à imprensa demonstrando o descaso das plataformas digitais em relação à precariedade do trabalho de seus trabalhadores, os quais desempenham um serviço fundamental para a sociedade brasileira ao contribuírem para a implementação e manutenção de medidas quarentenárias no contexto de pandemia. Segundo a FEMBRAPP, uma das plataformas declarou publicamente que possuía um colchão seguro de 10 bilhões em caixa para passar pela crise. Enquanto isso, os trabalhadores ligados a ela realizam longos tempos de trabalho, acompanhados de uma queda da remuneração, além de terem de custear por conta própria medidas de proteção.

Em oficio às plataformas digitais, a FEMBRAPP solicitou direitos mínimos aos trabalhadores diante do contexto pandêmico, com medidas como taxa zero durante 90 dias, antecipação do prêmio de produtividade anual, liberação de linha de crédito para pagamento após a pandemia, 
Precarização do trabalho e reorganização da mão de obra no contexto de pandemia | Aline da Costa Lourenço

auxílio de $R \$ 300$ para que o motorista possa passar 14 dias em casa em caso de contaminação por Covid-19, plano de saúde e ressarcimento do valor do álcool em gel e produtos de limpeza custeados pelo trabalhador. Entretanto, as empresas ignoraram todas as solicitações realizadas, demostrando o descaso com seus trabalhadores.

Diante deste cenário, trabalhadores auto-organizados se mobilizaram contra condições precárias de trabalho e realizaram uma paralisação dos entregadores no dia 1 de julho de 2020, que ficou conhecida como \#BrequeDosApps. Por meio do travamento em locais de saída de pedidos e mobilização na cidade, uma quantidade de entregadores neste dia não ligaram o aplicativo, além de envolvimento de usuários, com avaliações negativas dos aplicativos que baixaram consideravelmente sua "nota" nas plataformas de download ${ }^{3}$. A partir de então, surgiu a possibilidade dos trabalhadores montarem suas próprias plataformas, destacando-se os coletivos de entregadores e cooperativas de plataformas como alternativa à precarização imposta pelas plataformas.

De acordo com Scholz (2016), para que o cooperativismo de plataforma se desenvolva de forma eficaz deve-se passar por três fases. A primeira refere-se à recepção e a apropriação das tecnologias presentes nos aplicativos de entrega, a fim de colocar o trabalho em uma nova ideia de propriedade e valores democráticos. A segunda consiste na adoção de principios de solidariedade a fim de criar cooperativas multissetoriais, de propriedade dos trabalhadores ou plataformas cooperativas de propriedades. Por fim, deve-se focar na ressignificação de conceitos como inovação e eficiência, a fim de beneficiar a todos. $O$ autor considera que 0 cooperativismo de plataforma consiste em um termo que descreve alterações tecnológicas, culturais, políticas e sociais.

No Brasil, emergiram diversas plataformas cooperativas que foram destacadas pela newsletter DigiLabour sobre o mundo do trabalho e tecnologia, produzida por Rafael Grohmann. Foram apresentadas as

\footnotetext{
3 SCHAVELZON, Salvador. A luta dos entregadores de aplicativo contra os algoritmos autoritários. E1 país. 25 Jul 2020 Disponivel em: https://brasil.elpais.com/opiniao/2020-07-25/a-luta-dosentregadores-de-aplicativo-contra-os-algoritmos-autoritarios.html Acesso em: 6 novembro 2020.
} 
Precarização do trabalho e reorganização da mão de obra no contexto de pandemia | Aline da Costa Lourenço

cooperativas de entregadores já existentes no país, tais como, a Señoritas Courier, que consiste em um coletivo de mulheres e LGBT's ciclistas entregadoras em São Paulo, com cerca de 40 pessoas; a Pedal Express, um coletivo de entregadores ciclistas em Porto Alegre que objetivam construir alternativas mais sustentáveis e ecológicas; a Buscar Express, uma cooperativa de motoqueiros existente desde 1999 em Porto Alegre, com mais de 400 associados em atividade e que foi criada com o objetivo de atender clientes que não estão satisfeitos com as empresas tradicionais; o Ciclo Courier, uma empresa de gestão horizontal de entregas por bicicleta no Rio de Janeiro, desde 2012; a "Feme Express", um coletivo de mulheres motoqueiras na Grande São Paulo e a "Pedivento", um coletivo de entregadores na Grande Florianópolis que procura incentivar o ciclismo como alternativa sustentável à mobilidade urbana (DIGILABOUR, 2020).

Estas cooperativas supracitadas correspondem à formas de intermediação neste contexto, através da união dos trabalhadores que almejam melhores condições de trabalho.

\section{Considerações Finais}

De acordo com as páginas anteriores, verifica-se que, segundo Mattei e Heinen (2019), a economia brasileira vivenciou uma crise econômica a partir de 2015 que repercutiu na dinâmica do mercado de trabalho ao ponto de, em 2018, dobrar o número de desempregados se comparado ao registrado em 2012. Desde então, devido a recuperação lenta da crise, ocorreu uma ampliação da informalidade no mercado de trabalho. Desta forma, antes mesmo da pandemia, vários brasileiros se adaptaram à "uberização" como forma de trabalho.

Esta forma de ocupação vinculada a aplicativos é denominada por Abílio (2019) como "uberização" do trabalho e corresponde a uma nova forma de gestão, organização e controle do trabalho que se afirma como tendência global no mundo do trabalho, tendo as plataformas digitais como vetores de novas formas de organização do trabalho.

Com a pandemia as transformações tecnológicas e digitais foram aceleradas e fragilizaram as relações trabalhistas, dado que o trabalho 
Precarização do trabalho e reorganização da mão de obra no contexto de pandemia | Aline da Costa Lourenço

remoto e o trabalho por aplicativo aumentaram em meio as medidas quarentenárias. Esta tendência favorece o aumento das jornadas de trabalho, a volatilidade da renda e a perda de direitos trabalhistas mínimos. As plataformas digitais não reconhecem o vínculo empregatício para negar direitos e possibilitar o emprego pago por tarefas, o que faz o pagamento ser menor que o salário mínimo, além dos próprios trabalhadores terem que arcar com os equipamentos de proteção individual diante da pandemia.

Segundo Salomão (2020), com a pandemia no país ocorreu um aumento do número de entregadores de aplicativos, como na empresa Rappi, que teve um aumento de $300 \%$ do número de pedidos de cadastros de entregadores em sua plataforma, a 99Food teve um aumento de $20 \%$ no número de pedidos e o IFood constou com um aumento de 23 mil de entregadores registrados entre fevereiro e março de 2020.

Com base no estudo sobre as condições de trabalho de Entregadores via Plataforma Digital durante a pandemia da COVID-19, das principais empresas detentoras de plataformas digitais no Brasil, especialmente IFood, Uber Eats, Rappi e Loggi, realizado por Abílio et al., (2020), observou-se que houve a manutenção de longas horas de trabalho, somada à diminuição da remuneração desses trabalhadores e ao aumento do risco de contágio do virus, ampliando a precariedade e insegurança das condições de trabalho dos entregadores.

Dentro deste contexto, verifica-se que uma grande parcela da população historicamente não foi incluída no mercado de trabalho formal e que, diante da pandemia, os trabalhadores que se submetem aos trabalhos mediados por plataformas digitais se organizaram tanto por meio de manifestações para solicitar direitos mínimos de trabalho quanto com a criação de cooperativas.

\section{Referências:}

ABILIO, Ludmila Costhek. Uberização: Do empreendedorismo para o autogerenciamento subordinado. Psicoperspectivas, 18(3), 2019.

ABÍLIO, Ludmila Costhek; ALMEIDA, Paulo Freitas; AMORIM, Henrique; CARDOSO, Ana Claudia Moreira; FONSECA, Vanessa Patriota da; KALIL, Renan Bernardi; MACHADO, Sidnei. Condições de trabalho de entregadores via plataforma digital durante a Covid-19. Revista Jurídica Trabalho e 
Precarização do trabalho e reorganização da mão de obra no contexto de pandemia | Aline da Costa Lourenço

Desenvolvimento Humano, Campinas, EDIÇÃO ESPECIAL - DOSSIÊ COVID-19, p. 1-21, 2020.

ABILIO, Ludmila Costhek. Uberização: a era do trabalhador just-in-time? Estudos Avançados, 34 (98), 2020.

ANTUNES, Ricardo; FILGUEIRAS, Vitor. Plataformas digitais, Uberização do trabalho e regulação no Capitalismo contemporâneo. Contracampo, Niterói, v. 39, n. 1, p. 27-43, abr./jul. 2020.

BASTOS, P. P. Z. Ascensão e crise do governo Dilma Rousseff e o golpe de 2016: poder estrutural, contradição e ideologia. Rev. Econ. Contemp., núm. esp.: elocation - e172129, p. 1-63, 2017.

BIELSCHOWSKY, R. Estratégia de desenvolvimento e as três frentes de expansão no Brasil: um desenho conceitual. Presente e futuro do desenvolvimento brasileiro. A. Calixtre, A. Biancarelli, A. e M. A. Cintra (orgs.), Brasília, Instituto de Pesquisa Econômica Aplicada (IPEA), págs. 195225, 2014.

CARCANHOLO, Marcelo Dias. Inserção externa e vulnerabilidade da Economia brasileira no governo Lula. In: IV Encuentro Internacional Economia Politica y Derechos Humanos. Argentina: Buenos Aires, 2010.

CARDOSO, Adalberto Moreira. A Construção da Sociedade do Trabalho no Brasil. Uma investigação sobre a persistência secular das desigualdades. 2 ed. - Rio de Janeiro, Amazon, 2019.

CARDOSO JR, José Celso. Desmonte do Estado no governo Bolsonaro: menos república, menos democracia $\mathrm{e}$ menos desenvolvimento. In: POCHMANN, Marcio, AZEVEDO, Jose Sergio Gabrielli de (Org.) Brasil: incertezas e submissão? - São Paulo: Fundação Perseu Abramo, 2019.

CARNEIRO, Ricardo. Desenvolvimento em crise: a economia brasileira no último quarto do século XX. São Paulo: Editora UNESP, IE- Unicamp, 2002.

CARVALHO, Laura. Valsa Brasileira: Do boom ao caos econômico. São Paulo: Todavia, 2018.

CARVAlHO, Laura. Curto-Circuito: O virus e a volta do Estado. São Paulo: Todavia, $1^{\mathrm{a}}$ edição, 2020.

CASTRO. Barros de Castro. Esperança, Frustração e Aprendizado: A História da Nova República. In: Giambiagi, F. Economia Brasileira Contemporânea, 2016.

DEPARTAMENTO INTERSINDICAL DE ESTATÍSTICA E ESTUDOS SOCIOECONOMMICOS (DIEESE). Contratos intermitentes na gaveta. Boletim 
Precarização do trabalho e reorganização da mão de obra no contexto de pandemia | Aline da Costa Lourenço

Emprego em pauta. $\mathrm{N}^{\mathrm{o}} 14$, jan./2020 Disponivel em: https://www.dieese.org.br/boletimempregoempauta/2020/boletimEmprego EmPauta14.pdf Acesso em: 27 outubro 2020.

DIGILABOUR. Coletivos e cooperativas de entregadores no Brasil. DigiLabour. $\quad$ Jul. 2020. Disponivel em: < https://digilabour.com.br/2020/07/26/coletivos-e-cooperativasdeentregadores-no-brasil/>. Acesso em: 05 novembro 2020.

FEMBRAPP. Nota à imprensa $\mathbf{n}^{\circ}$ 01/2020. Disponivel em: https://drive.google.com/file/d/1EWHBCDP31_1eTKoFwuj-VRj-

1 CsTfuEs/view Acesso em: 06 novembro 2020.

FONTES, Virginia. Capitalismo em tempos de uberização: do emprego ao trabalho. Revista KALLAIKIA - Revista de Estudos Galegos, $n^{\circ} 2$, junho de 2017.

HERMANN, Jennifer. Auge e Declínio do Modelo de Crescimento com Endividamento: O II PND e a Crise da Divida Externa In: Giambiagi, F. Economia Brasileira Contemporânea, 2016.

MATTEI, Lauro; HEINEN, Vicente Loeblein. Panorama do mercado de trabalho brasileiro entre 2012 e 2018. Anais do XXIV Encontro Nacional de Economia Politica. 2019.

MEDEIROS, Carlos Aguiar de. A economia brasileira no novo milênio: continuidade e mudanças nas estratégias de desenvolvimento. Revista de Economia contemporânea, v. 21, p. 1-16, 2017.

MELLO, Guilherme; ROSSI, Pedro. Do industrialismo à austeridade: a política macro dos governos Dilma. In: Para além da politica econômica. Organizado por Ricardo Carneiro, Paulo Baltar, Fernando Sarti. São Paulo: Editora Unesp Digital, 2018.

NASSIF, André. Tripé Macroeconômico: Limites e Propostas de Mudança. Revista Politica social e desenvolvimento. Abril, 2015.

OREIRO, J.L. e PAULA, L.F. (2019). A economia brasileira no governo Temer e Bolsonaro: Uma avaliação preliminar, mimeo.

PNAD Covid

19. https://biblioteca.ibge.gov.br/visualizacao/livros/liv101755.pdf

POCHMANN, Marcio. Ajuste econômico e desemprego recente no Brasil metropolitano. Estudos Avançados 29 (85), 2015.

RUGITSKY, Fernando. Milagre, miragem, antimilagre: A economia politica dos governos Lula e as raízes da crise atual. Revista Fevereiro. 2016.

SALOMÃO, Karin. iFood e Rappi: mais entregadores (e mais cobrança por apoio) na pandemia. Exame, abr., 2020. Disponivel em: 
Precarização do trabalho e reorganização da mão de obra no contexto de pandemia | Aline da Costa Lourenço

$<$ https://exame.com/negocios/coronavirus-levamais-entregadores-egorjetas-aos-apps-de-delivery/>. Acesso em: 05 novembro 2020.

SCHAVELZON, Salvador. A luta dos entregadores de aplicativo contra os algoritmos autoritários. El pais. Disponivel em: https://brasil.elpais.com/opiniao/2020-07-25/a-luta-dos-entregadores-deaplicativo-contra-os-algoritmos-autoritarios.html Acesso em: 6 novembro 2020.

SCHOLZ, Trebor. Cooperativismo de plataforma: contestando a economia do compartilhamento corporativa. Tradução e comentários Rafael A. F. Zanatta. São Paulo: Fundação Rosa Luxemburgo; Editora Elefante; Autonomia Literária, 2016.

SERRANO, Franklin; SUMMA, Ricardo. Conflito distributivo e o fim da "breve era de outro" da economia brasileira. Novos estudos. CEBRAP. São Paulo. V37n02. 175-189. Maio-ago. 2018. 